us when he says, "May I echo Keynes, who believed that 'any rule-of-thumb in surgery is wholly pernicious'." Perhaps Mr. Murley failed to read the unconscious plagiarism in our final paragraph: "Our results suggest that there is no one treatment that should be applied exclusively to all cases of cancer of the breast at the stage of the disease when radical mastectomy is a practicable proposition"-which, incidentally, was our definition of "the early case." We conclude: "The importance of clinical staging would seem to be decisive, and this would imply the exercise of clinical judgement and the value of experience."

Statistics.-Drs. Edelstyn and MacRae (2 September, p. 587) object that the statistical analysis was not spelt out. We apologize for this but the statistics, worked out by $\mathrm{Mr}$. Michael Feldstein, of the Department of Statistics of the University of Buffalo, and Dr. Clive Spicer, of the M.R.C. Computer Unit, covered many pages of foolscap and it would have been impracticable to publish them in full. However, we agree that a more detailed account of the statistical methods as an appendix might have been helpful. Drs. Edelstyn and MacRae are more than welcome to study the analysis. In answer to their query, "Was it decided to analyse at the 10-year point or when 370 patients were admitted to the trial, and when was this decision made?", the decision was made 10 years ago when the trial started and the time for analysis is clearly stated in our paragraph entitled "Criteria for Conclusion of the Trial"-namely, when any part of the trial gave a "determinant" result.

Radiotherapy.-We pointed out that the dose of radiotherapy used for the axilla was 2,5002,700 rads in both sides of the series, but in patients having a radical mastectomy the dose was given in 18 days and in those having a tylectomy in 12 days. At the beginning of a preliminary trial 20 years ago both the radical mastectomy and tylectomy patients were treated

in 12 days to a dose of 2,700 rads to the axilla, but it was found that after a radical mastectomy the axilla became unduly sore with this dosage, so the time was prolonged to 18 days in these cases. Also at this time 4,000 rads were used for the breast. But this caused a significant degree of morbidity and it seemed futile to try to preserve a breast if after five years it became an unsightly, fibrosed, and tender organ: therefore, the dose was reduced to 3,500 rads.

We thought the dosage for patients who had undergone minimal surgery should not be so high as to cause more discomfort than a radical mastectomy, nor should it be so high that fat necrosis, fibrosis of the breast, and unsightly telangiectasis occurred. Drs. Edelstyn and MacRae are, of course, right in saying the difference in time alters the biological effect. As we said in the paper, "both groups of patients had radiotherapy but because of the different operative procedures the method of delivery had to be slightly different." Nevertheless, as the factors in each side of the tria were kept constant the comparison is valid.

Mr. E. S. Lee and his colleagues say our radiotherapy is suboptimal, and we do not know what they mean by this. To us optimal includes minimal discomfort to the patient, and we feel the dosage cannot be increased very much without causing a considerable increase in morbidity and discomfort. If it is necessary to increase the dose to improve results we think it would be better for the patients to have axillary clearance by surgery.

Finally, we were much averse from drawing conclusions from our data, but it seems that conclusions are expected from us and we might summarize as follows. From a trial comparing extended tylectomy plus radiotherapy with radical mastectomy plus radiotherapy, in doses and techniques as described, the survival rate of patients with clinical stage-2 tumours appears better after radical mastectomy, and hence this operation is to be preferred (though not neces- sarily the best available treatment). In stage-1 cases extended tylectomy, despite the frequency of local recurrences, is less disturbing to the patient and may provide as good, perhaps better, chance of survival than radical mastectomy. In thin women simple mastectomy may be cosmetically preferable. -We are, etc.,

Hedley Atrins JOHN HAYWARD D. J. KIUgman Guy's Hospital,

A. B. WAYTE

\section{Gas Gangrene and Hyperbaric Oxygen}

SIR,-We are in agreement with your leading article (23 September, p. 715) pointing out that hyperbaric oxygen therapy has been a significant advance in the treatment of this difficult clinical condition. In our view, however, some reference to the results obtained in treating these patients in small, one-man chambers should have been made. Using small one-man hyperbaric chambers many workers, including ouselves, ${ }^{1-6}$ have reported findings which are not dissimilar to those of Roding and others ${ }^{7}$ and several other groups, ${ }^{8-11}$ using the large chamber. Before agreeing that a further large chamber should be provided we would have preferred that their superiority should have been established. Large chambers are costly and may carry a risk to the medical attendant. The money might better be spent in providing one-man chambers at a number of selected centres.-We are, etc.,

\section{J. B. BOURKE}

Surgical Unit,

London Hospital

H. D. RITCHIE

1 Hanson, G. C., Slack, w. K., Chew, H. E. R. and Thomas, D. A., Postgraduate Medical Van Zyl, J. J. W., Maartens, P. R., and Du Toit, F. D., in Proceedings of the Third International Conference on Hyperbaric Medicine, ed I. W. Brown, and B. G. Cox. Washington, Research Council, 1966

3 Colwill, M. R., and Maudsley, R. H., foumal of Bone and foint Surgery, 1968, $50 \mathrm{~B}$, 732.
Slack, W. K., Hanson, G. C., and Chew, H. E. R., British fournal of Surgery, 1969, 56, 505 . R., and Strunin, Ritchie, H. D., Simpson, B. R. and Strunin, L.., Fournal of the Royal Coll

6 Ritchie, H. D., Lyon Chirurgical, 1972, 68, 85. I., Surgery, Gynaecology and Obstetrics, 1972, 134,579 .

8 Brummelkamp, W. H., Hogendijk, J. L., and Boerema, I., Surgery, 1961, 49, 299. . J., and Hitchcock, C. R. in Proceedings of the Third
Medicine, ed. I. W. Brown, and B. G. Cox. Washington, D.C.' National Academy of 10 Glad, R. M., Bouhoutsos, D. C., and Douglass, F. M. 230 .

11 Hitchcock, C. R., Haglin, J. R., and Arnar, O., Surgery, 1967, 62, 759 .

SIR,-Few would disagree with your leading article (23 September, p. 715) that there is need for a centrally placed hyperbaric chamber for the treatment of gas gangrene. Indeed, the indications for hyperbaric oxygen are now so protean and embrace so many branches of medicine and surgery 1 that the provision of chambers throughout the country now requires serious consideration. You emphasize the advantages of large chambers and mention the disadvantages of high capital and running costs. In a large general hospital, however, several small chambers will be required to cope with the volume of work and the expenditure will then approach that of a large complex.

There are certain advantages in small, oneman chambers. They can be operated by one person after a short training. Each patient receives $100 \%$ oxygen at the prescribed oxygen tension, which is seldom possible with a mask. The "bends" are not a problem to the patient, as at no time does he breath compressed air. Claustrophobia must be added to the disadvantages of small chambers which you mention, but to many patients these considerations are unimportant.

Your view that large chambers are safer than small does not appear to be born out by the literature. Twenty-one accidental deaths in large chambers have been reported $^{2}$ (albeit in a military rather than a clinical context), while I have been able to trace only three accidental fatalities occurring in small chambers. I have attempted to combine the advantages of both systems in a compromise design.

An access compartment (on left in Fig.) acts as an airlock and is pressurized with air. It can be used for outpatients not requiring individual attention. Ambulant patients with, for example claudication, rest pain, chronic osteomyelitis, and diabetic lesions would attend for treatment in batches and breath oxygen delivered from a mask (or, more efficiently, a helmet).

The main chamber is compressed with air and contains the attendants during their watch. At this pressure the diving tables ${ }^{3}$ are not entered and there is no need for staged decompression. To this compartment are attached several capsules with doors at each end. Patients are inserted into their capsule from without while required pressure of oxygen circulated. If the patient requires attention the pressure in the capsule is equilibrated with the main chamber, the inner door is opened, the patient 